\title{
Demographic cost and mechanisms of adaptation to environmental stress in resurrected Daphnia
}

\author{
Stefan SOMMER, ${ }^{1}$ Roberta PISCIA, ${ }^{2}$ Marina M. MANCA, ${ }^{2}$ Diego FONTANETO,${ }^{2}$ Arpat OZGUL ${ }^{1 *}$ \\ ${ }^{1}$ Department of Evolutionary Biology and Environmental Studies, University of Zürich, Winterthurerstrasse 190, 8057 Zürich, Switzer- \\ land; ${ }^{2}$ National Research Council, Institute of Ecosystem Study, Largo Tonolli 50, 28922 Verbania Pallanza, Italy \\ *Corresponding author: arpat.ozgul@ieu.uzh.ch
}

\begin{abstract}
A characteristic feature of the Daphnia (Crustacea: Cladocera) life cycle are the so-called ephippia, which are fertilised eggs that need to undergo diapause. When they are shed by the female, they sink to the lake bottom, where they may become embedded in the sediment and may remain viable for decades. Extracting and hatching ephippia in the laboratory and subjecting resurrected lineages to conditions representative of historic lake environments allows retrospective investigation of life-history responses to environmental change. Here we reanalyse data from such a resurrection experiment. Contemporary and past lineages of Daphnia galeata Sars 1863 were obtained from Lake Orta (Italy), a deep, subalpine lake with a well-documented history of industrial copper pollution. Experimental Daphnia were subjected to three copper treatments representative of two levels of historic as well as to current (i.e., unpolluted) lake conditions, and life-table data were collected. With these data at hand, we first estimated vital rates (survival, maturation, and reproduction) and used these rates to project the asymptotic population growth rates ( $\lambda$ ) for each population-by-treatment combination. Next, we performed a retrospective decomposition to estimate the contributions of the vital rates to observed differences in $\lambda$. Finally, we used elasticity analysis to explore the functional relationship between $\lambda$ and each of the vital rates. We found that survival rates were only compromised at elevated copper levels. Moreover, past, resurrected Daphnia had a higher $\lambda$ at low copper concentrations compared to unpolluted conditions, but a lower $\lambda$ when exposed to high copper levels. Contemporary Daphnia, on the other hand, only reproduced successfully in unpolluted water. Under these conditions, however, they had a higher population growth rate than the past Daphnia, suggesting a cost of copper tolerance in the latter. This cost was mainly due to a lower probability of reproduction and reduced fecundity, whereas survival rates contributed only little to differences in $\lambda$. Finally, we found higher elasticity values of $\lambda$ to survival than to reproductive rates. This suggests that any change in the environment that will affect survival rather than reproductive parameters will have a much larger impact on Lake Orta's current Daphnia population.
\end{abstract}

Key words: Cladocera; copper pollution; Lake Orta; life-history responses; perturbation analyses; population ecology.

Received: July 2015. Accepted: October 2015.

\section{INTRODUCTION}

The persistence of natural populations in changing environments depends on their ability to adapt (Chevin et al., 2010). Adaptive responses to changing conditions can be through plastic and/or genetic mechanisms (Merilä and Hendry, 2014), which may affect a variety of life-history traits, resulting in distinct phenotypic and demographic signatures (Ozgul et al., 2009; Coulson et al., 2010). While plastic responses are fast and occur at the level of the individual, genetic adaptation is comparatively slow as it represents a multi-generation, population-level response. Nevertheless, in contaminated environments adaptive evolution can occur within a few generations (Medina et al., 2007) and may be investigated retrospectively in the context of resurrection ecology (Kerfoot $e t$ al., 1999; Orsini et al., 2013).

A case in point of a rapidly changing environment is Lake Orta in Northern Italy. During the last century, the lake was severely affected by industrial pollution and as such has become a model ecosystem for studies of the effects of heavy-metal pollution on the lake's water chemistry and its biota (Calderoni et al., 1992; Bonacina and Baudo, 2001). From 1926 onwards, disposal of copperand ammonium-sulphate contaminated wastewater of a newly built rayon factory led to a gradual increase of ionic copper and to a steady acidification of the lake with negative effects on all taxonomic groups; within only three years, phytoplankton, zooplankton, and finally fish disappeared (Bonacina, 2001a). In the late 1950s, copper contamination was markedly reduced (Calderoni et al., 1992). As a result, copper levels steadily dropped until the late 1960s, remained fairly constant throughout the 1970s, and decreased again upon the enactment of a new law in 1980, which regulated the discharge of industrial wastewater into Italian lakes. The water quality improved further after whole-lake liming between May 1989 and June 1990. Ten years after these liming efforts, copper was virtually absent from the water column and the $\mathrm{pH}$ value had returned to neutral levels (Bonacina, 2001b). 
Recolonisation of Lake Orta by Daphnia started in the 1980s when the lake was still highly acidic (Calderoni et al., 1992; Bonacina and Pasteris, 2001). Electrophoretic studies revealed that the population consisted of a single clone of Daphnia obtusa Kurz 1875 (Bachiorri et al., 1991). In 1989, a Daphnia species of the D. longispina group - later identified as Daphnia galeata Sars 1863 (Piscia et al., 2015) - colonized the lake and, as water quality improved rapidly after liming, eventually (in 1996) replaced D. obtusa from the pelagic community (Bonacina and Pasteris, 2001). High sensitivity of $D$. galeata to acidic conditions likely prevented this species from establishing a viable population in the lake at an earlier stage (Ponti et al., 2010). Allozyme analyses conducted on individuals collected in 2006 revealed an extremely low clonal diversity in the lake's population, corroborating the assumption of recent colonisation in combination with strong clonal selection (Piscia et al., 2006).

In a recent study on Lake Orta Daphnia, Piscia et al. (2015) compared the life histories of contemporary and ca. 25-year old lineages of D. galeata exposed to different levels of copper pollution. Specifically, Piscia et al. (2015) subjected laboratory-reared offspring from contemporary individuals from the now unpolluted lake and offspring from past, resurrected Daphnia - the latter obtained from ephippia found in sediments deposited during the early phases of lake recovery - to two concentrations of copper, representing early (high pollution) and late (low pollution) phases of lake recovery as well as to current (unpolluted) conditions. By recording life-table data of individually kept Daphnia, Piscia et al. (2015) found that the low-copper treatment had no significant effect on survival and reproduction of past Daphnia when compared to unpolluted conditions, whereas high levels of copper delayed the onset of reproduction, reduced the fecundity, and led to smaller offspring compared to both the unpolluted and the low-copper environment. Contemporary individuals, on the other hand, failed to produce viable offspring at elevated copper concentrations. In unpolluted lake water, however, contemporary Daphnia had a higher fecundity than past Daphnia, suggesting a cost of copper tolerance in the resurrected individuals (Piscia et al., 2015).

In this study, we reanalyse the data of Piscia et al. (2015) in a biodemographic framework in an attempt to unravel the underlying mechanisms of the observed differences in copper adaptation and the costs associated with increased tolerance in past, resurrected Daphnia. Such a mechanistic understanding of population dynamics is a valuable tool for predicting how populations might respond to future environmental change, a topic that is of increasing importance in the face of global climate change (Petchey et al., 2015).

\section{METHODS}

In this section, we give only a brief summary of the experimental procedures. A detailed description of the laboratory methods can be found in Piscia et al. (2015).

Contemporary D. galeata were collected in Lake Orta in April 2011 at a depth of 0-50 m. Past D. galeata were obtained from ephippia extracted from sediment layers deposited between 1986 and 1992 (sediment core ORTA 07/1A: Piscia et al., 2012). During this period, lake copper concentrations were in the range of $30-40 \mu \mathrm{g} \mathrm{Cu}$ (II) $\mathrm{L}^{-1}$. The ephippia were induced to hatch in the laboratory at the Institute of Ecosystem Study in Verbania Pallanza, Italy. Clones of both contemporary and past Daphnia were cultured in filtered $(0.45 \mu \mathrm{m})$ Lake Orta surface water at a temperature of $20( \pm 1){ }^{\circ} \mathrm{C}$ and a light/dark regime of $16 \mathrm{~h} / 8 \mathrm{~h}$. They were fed with green algae, Kirchneriella subcapitata Korshikov 1953, at a density of about $22 \times 10^{3}$ cells $\mathrm{mL}^{-1} \mathrm{~d}^{-1}$. All clones were acclimated to laboratory conditions until the $\mathrm{F} 3$ generation to avoid maternal effects (Lampert, 2001).

Experimental Daphnia were taken from the F4 generation. Thirty neonates (max. $24 \mathrm{~h}$ old) from both the contemporary and the past lineages were individually exposed to either $40 \mu \mathrm{g} \mathrm{Cu}$ (II) $\mathrm{L}^{-1}, 10 \mu \mathrm{g} \mathrm{Cu}$ (II) $\mathrm{L}^{-1}$ or to unpolluted lake water. Individual Daphnia (10 each per population and treatment) were kept in $100 \mathrm{~mL}$ of filtered $(1.2 \mu \mathrm{m})$, copper-adjusted lake water, which was renewed every other day. Survival, number of eggs, and number of offspring produced per day and per female were recorded throughout the entire lifespan of each individual.

Daphnia exhibit different survival and reproductive rates between juvenile and adult stages (Hülsmann and Weiler, 2000; Hülsmann and Voigt, 2002). Consequently, we constructed a two-stage-structured matrix model to investigate the dynamics of contemporary and past populations in each treatment:

$\left[\begin{array}{l}N_{J} \\ N_{A}\end{array}\right]_{t+1}=\left[\begin{array}{cc}S_{J}(1-M) & S_{A} R E \\ S_{J} M & S_{A}\end{array}\right]\left[\begin{array}{l}N_{J} \\ N_{A}\end{array}\right]_{t}$

where $S_{J}$ and $S_{A}$ are the respective probabilities of an individual in the juvenile (i.e., pre-reproductive) and the adult stage surviving until the following day, $M$ - the inverse of juvenile developmental time - is the probability of a juvenile maturing to the adult stage, $R$ is the daily reproduction probability of an adult, and $E$ is the average number of eggs an adult Daphnia will produce per reproductive event. $N_{J}$ and $N_{A}$ are the elements of the population vector at a given time step indicating the number of individuals in each life-history stage. Matrix multiplication of the projection matrix with the population vector at time $t$ produces the population vector at the next time step, $t+1$. As all demographic rates are estimated daily, projection time interval is also one day.

The stage-specific daily survival $\left(S_{J}, S_{A}\right)$, maturation 
$(M)$, and reproduction $(R)$ probabilities were estimated using generalised linear mixed effect models with the binomial error distribution, and the number of eggs $(E)$ with the Poisson error distribution (Bolker et al., 2009). Each model included population, treatment, and their interaction as fixed effects and individual as the random effect on the intercept. Resulting models were used to estimate the mean rates for all population-by-treatment combinations. The asymptotic population growth rate $(\lambda)$ for each population-by-treatment combination was estimated as the dominant eigenvalue of the projection matrix parameterised using the estimates of the respective vital rates.

Prospective perturbation analyses are used to investigate the functional relationship between the asymptotic population growth rate $\lambda$ and the vital rates (Caswell, $2001)$; that is, they explore how much $\lambda$ changes in response to proposed changes in one or more of the vital rates. As such, prospective analyses predict the consequences for $\lambda$ of future changes in vital rates. Elasticity analysis, a widely used prospective perturbation, measures the sensitivity of $\lambda$ to a proportional change in a given matrix element (Benton and Grant, 1999) and therefore enables meaningful comparisons between different matrix elements. Elasticity analysis can be extended to determine the sensitivity of $\lambda$ to proportional changes in lower-level parameters underlying each matrix element such as the vital rates (Caswell, 2001). Lower-level elasticities for Daphnia vital rates were calculated as:

$\frac{x}{\lambda} \frac{\partial \lambda}{\partial x}=\frac{x}{\lambda} \sum_{i, j} \frac{\partial \lambda}{\partial a_{i j}} \frac{\partial a_{i j}}{\partial x}$

where $a_{i j}$ is the matrix element in row $i$ and column $j$, and $x$ is a lower-level parameter (i.e., a vital rate).

Retrospective decomposition analyses, on the other hand, are used to investigate how $\lambda$ changes in response to observed (i.e., past) changes in the vital rates (Caswell, 2001). The approach quantifies the change in an input parameter and the sensitivity (i.e., the partial derivative) of the response parameter to this input parameter. The actual contribution of the input to observed change in the response is calculated as the product of the change in the input and the sensitivity of the response to input. Although originally developed for the decomposition of the $\lambda$, the approach has found a wider use in other ecological (Polishchuk and Vijverberg, 2005; Young et al., 2011) and evolutionary (Hairston et al., 2005; Ellner et al., 2011) contexts. If a vital rate did not change, its contribution to observed change in $\lambda$ is zero (e.g., juvenile survival probability $S_{J}$, see below). Using fixed one-way life-table response experiments (LTRE), a commonly used retrospective perturbation analysis (Caswell, 2000), we investigated the demographic causes of differences in $\lambda$ between pairs of population-by-treatment combinations. Using a control as a reference matrix (i.e., as the matrix at which the sensitivities were evaluated), the observed difference in $\lambda(\Delta \lambda)$ between the control and a treatment matrix is decomposed into contributions from each of the five vital rates $\left(x_{i}\right)$ as:

$$
\Delta \lambda=\lambda^{(t)}-\lambda^{(c)} \approx \sum_{i}\left(x_{i}^{(t)}-x_{i}^{(c)}\right) \frac{\partial \lambda}{\partial x_{i}^{(c)}}
$$

where superscripts $t$ and $c$ indicate the treatment and control matrices, respectively. Although $R$ and $E$ are included in the population projection matrix as a product, these two biological processes are accounted for separately as they can be differentially affected by treatments and, in turn, differentially affect the resulting $\lambda$. As a consequence, the prospective perturbation analyses will always give the same results for the two parameters, whereas retrospective decomposition will highlight the differences in their contribution.

We incorporated parameter uncertainty into our demographic analyses via a parametric bootstrap method (Efron and Tibshirani, 1993), where we randomly sampled the life-history data of ten individuals - with replacement from each of the population-by-treatment combinations. The resulting distributions of vital rates, population growth rates, lower-level elasticities, and LTRE contributions were estimated using data from 500 bootstraps and are presented as boxplots in figures. All analyses were performed using the statistical and programming language R (Version 3.2; R Development Core Team, 2014) and the GLMM package lme4 (Version 1.1; Bates et al., 2015).

\section{RESULTS AND DISCUSSION}

Contemporary Daphnia reproduced successfully only in unpolluted water and died at elevated copper concentrations on day 10 (Piscia et al., 2015). In our analyses, we included data of the remaining four population-by-treatment combinations: contemporary-unpolluted (CU), past-unpolluted (PU), past-low copper (PL), and past-high copper (PH).

First, we estimated the vital rates (Fig. 1). All of the juveniles survived to the adult stage except one individual at the high copper concentration. Consequently, we assumed perfect juvenile survival across the four population-by-treatment combinations. Adult survival was the highest in past, resurrected Daphnia in the unpolluted treatment, but decreased with increasing pollution to values below that of contemporary Daphnia in the unpolluted treatment. Maturation was fastest in contemporary individuals in the unpolluted treatment and slowed down considerably in past Daphnia and with increasing copper concentration to levels below that of contemporary individuals. Furthermore, the probability of reproduction and the number of eggs produced by each female per reproductive event were highest in contemporary individuals. Interestingly, in past Daphnia, these rates were higher at the low copper concentration compared to both the unpolluted and the high-copper treatment, suggesting a tradeoff between survival/maturation and reproduction/ 
fecundity. All these results are compatible with previous results for longevity, age at first reproduction, and fecundity of the two Daphnia populations (Piscia et al., 2015).

Second, we used the vital rates to parameterise a stagestructured population matrix in order to estimate the asymptotic population growth rates $\lambda$ for each population-by-treatment combination. We found that all $\lambda$ were significantly larger than one (Fig. 2), indicating that populations were increasing in size. However, high copper levels substantially slowed down population growth in past, resurrected Daphnia. Under unpolluted conditions, fast maturation and high reproductive rates of contemporary individuals translated directly into rapid asymptotic population growth. In fact, in the unpolluted treatment, the $\lambda$ of the contemporary population was higher than the $\lambda$ of past Daphnia, indicating genetic differences between populations (Lopes et al., 2004) and a cost of copper tolerance in the latter population. The magnitude of that $\operatorname{cost}(\Delta \lambda)$ was roughly 0.2 (Fig. 2). Interestingly, past Daphnia performed better at the low copper concentration than under unpolluted conditions, suggesting that the two populations might have adapted to the copper levels they experienced in nature (Piscia et al., 2015).

Next, using the LTRE analysis, we compared projection matrices pairwise (Fig. 3) in order to unravel the relative contribution of each vital rate to the observed differences in $\lambda$. Comparison of contemporary and past, resurrected Daphnia (CU vs PU and CU vs PL) gives an idea about the demographic costs of copper tolerance in past Daphnia. We found that reproductive rates in the past population were compromised in order to maintain adult survival (Fig. 3). Specifically, lower $\lambda$ in the PU and the $\mathrm{PL}$ populations, compared to the $\mathrm{CU}$ population, were mainly caused by a lower probability of reproduction, followed by fewer eggs produced per reproductive event and by delayed maturation. In past Daphnia, the slightly higher $\lambda$ at the low-copper concentration, compared to the unpolluted treatment (PU vs PL), was due to an increase in the probability of reproduction and egg number. The positive effects of these two vital rates on $\lambda$ outweighed the negative effect of delayed maturation. The decline in $\lambda$ at the high copper concentration, on the other hand, was largely caused by negative effects of all three reproductive rates (i.e., by delayed maturation, a decline in egg number, and a lower probability of reproduction; PL $v s$ PH in Fig. $3)$. Adult survival probability had only a marginal effect on differences in $\lambda$, whereas juvenile survival had no effect at all as it did not vary between populations or treatments $\left(S_{J}=1\right.$, see above).

Finally, we performed elasticity analyses for each population-by-treatment combination to explore the functional relationship between the asymptotic population growth rate $\lambda$ and each of the vital rates (Fig. 4); the higher the elasticity of $\lambda$ to a given vital rate, the larger the effect

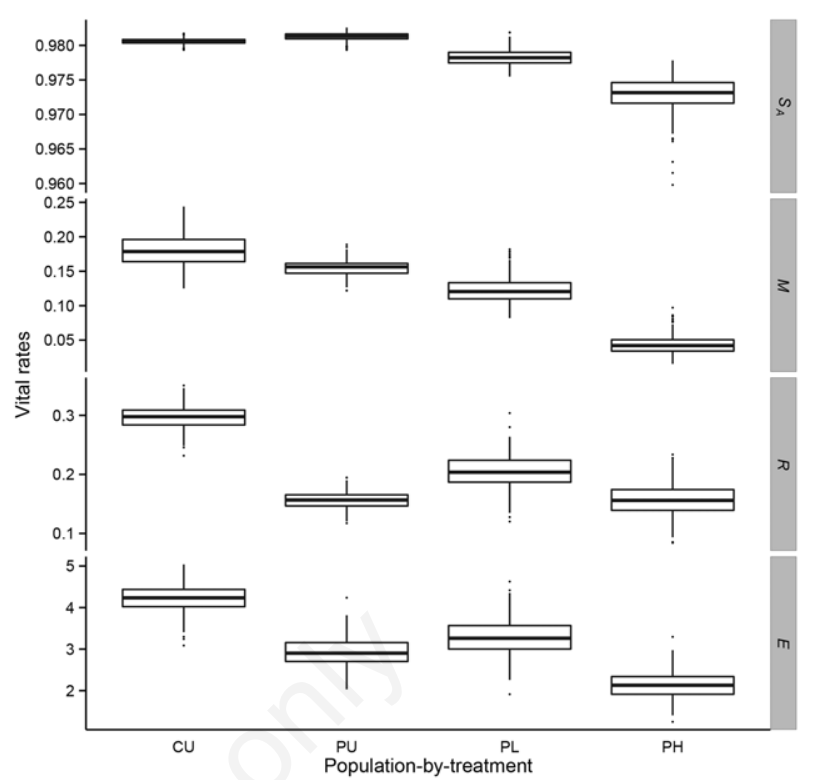

Fig. 1. Estimated vital rates of contemporary and past Daphnia. Shown are the probabilities of adult survival $\left(S_{A}\right)$, maturation $(M)$, and reproduction $(R)$ as well as the number of eggs produced per female per reproductive event $(E)$ for the contemporary-unpolluted $(\mathrm{CU})$, the past-unpolluted $(\mathrm{PU})$, the past-low copper (PL), and the past-high copper (PH) Daphnia. Juvenile survival probability $\left(S_{j}\right.$; not displayed) was assumed to per perfect (see text for details). Lower and upper edges of boxes are the first and third quartiles, respectively. Lines inside the boxes are median values. Whiskers above and below the boxes extend to maximally 1.5 times the interquartile range; dots beyond whiskers depict outliers.

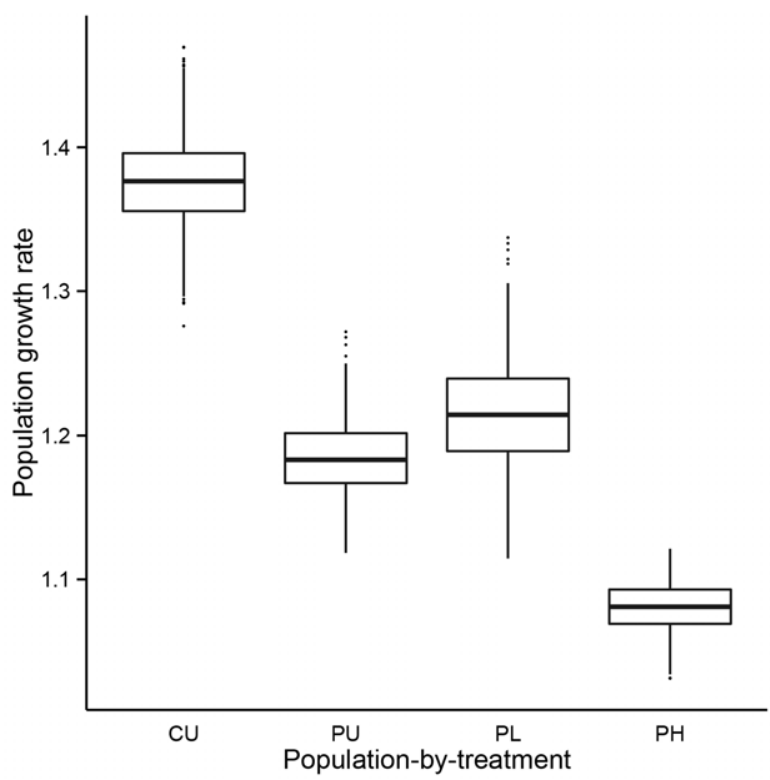

Fig. 2. Estimated asymptotic population growth rate of contemporary and past Daphnia. Boxplot conventions and acronyms are as in Fig. 1. 
of an equal proportional change in that vital rate on $\lambda$. We found that $\lambda$ was considerably more elastic to adult and juvenile survival probability than to any of the three reproductive rates, with maturation consistently ranking lowest. Elasticity values to survival rates were similar between the populations with the highest growth rates $(\mathrm{CU}$ and PL), but differed more among the different treatments in past Daphnia. Interestingly, when we pushed past Daphnia outside their preferred environment - the low copper treatment - elasticity patterns changed in different directions. Under unpolluted conditions (PU), elasticity of $\lambda$ to adult survival probability increased, while that to juvenile survival decreased; the opposite pattern was observed at increased copper concentrations (PH). The elasticity values for reproductive rates changed in the same direction, but they were consistently lower than in the contemporary Daphnia.

While LTRE analysis provides a retrospective look at change, elasticity values are used in a prospective framework; for a given population, they predict how changes in the vital rates (e.g., caused by environmental change) would lead to a change in the asymptotic growth rate of that population (Caswell, 2000). As for the contemporary Daphnia population, our results imply that future changes in Lake Orta water conditions will have a bigger impact on the Daphnia population dynamics, if survival rather than reproduction was affected by the change. Using resurrectionecology methods, predictions like these could theoretically also be examined retrospectively by testing Daphnia from progressively younger sediments, provided that past environmental changes and their effects on Daphnia vital rates were known. We currently lack such information.

\section{CONCLUSIONS}

We estimated vital rates of contemporary and past, resurrected Lake Orta Daphnia exposed to different copper concentrations and used these estimates to project the asymptotic population growth rates $\lambda$. Additionally, we performed retrospective (LTRE) and prospective (elasticity) perturbation analyses (Caswell, 2000) in order to gain a mechanistic understanding of the population dynamics. Our estimates of vital rates are in line with previous results for longevity, age at first reproduction, and fecundity for the same individuals (Piscia et al., 2015). Generally, contemporary Daphnia in the unpolluted treatment outperformed past Daphnia regardless of the copper level, but they failed to produce viable offspring in both copper treatments. Interestingly, past Daphnia performed best at low copper levels, suggesting that each of the populations might have adapted to the specific copper levels they experienced at the time they were present in Lake Orta. However, the reduced performance (lower $\lambda$ ) of past Daphnia compared to contemporary individuals implies a demographic cost of copper tolerance in the former pop- ulation. This cost came in the form of impaired reproduction. Differences in survival rates, on the other hand, contributed only little to differences in $\lambda$. Finally, elasticity values of $\lambda$ were much higher to survival than to repro-

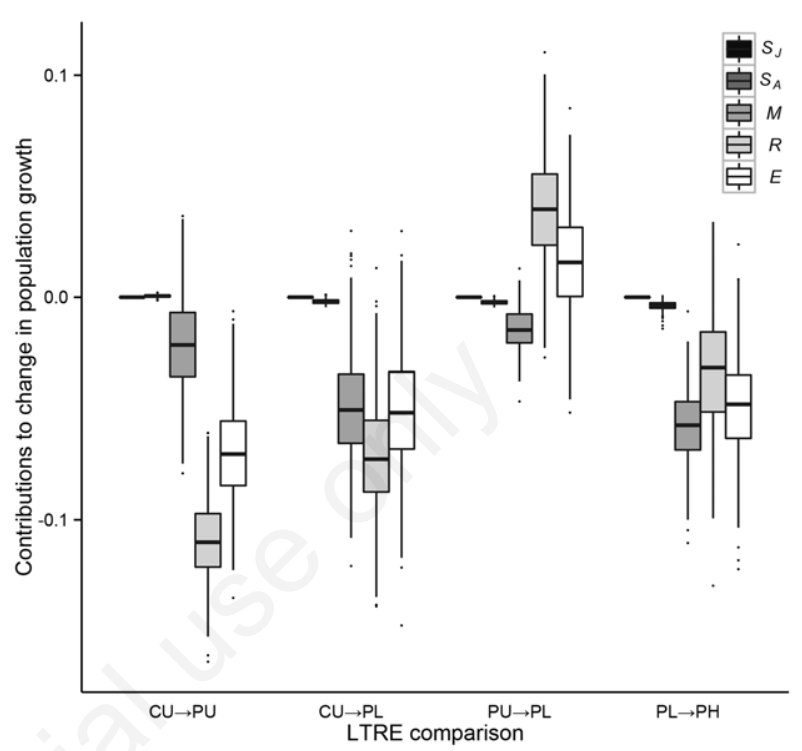

Fig. 3. Life-table response experiments. Contributions of the vital rates to differences in asymptotic population growth rate between population-by-treatment combinations. Boxplot conventions and acronyms are as in Fig. 1.

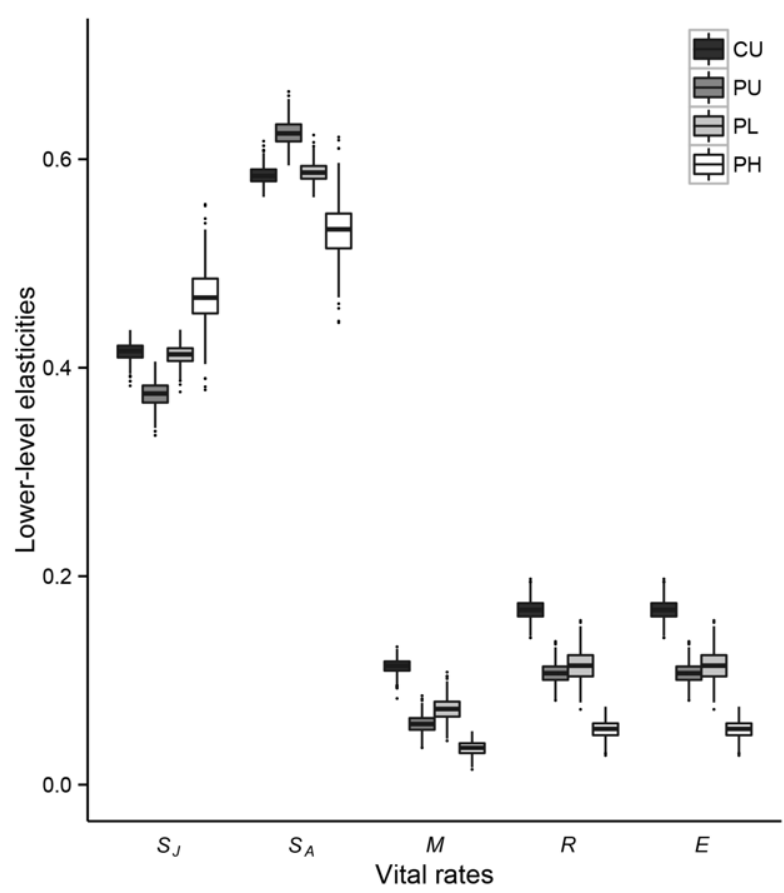

Fig. 4. Elasticity analysis. Lower-level elasticities for Daphnia vital rates. Boxplot conventions and acronyms are as in Fig. 1. 
ductive rates. Our results therefore suggest that the current Lake Orta Daphnia population will be more affected by future environmental change, if such change affected the survival probabilities rather than the reproductive rates.

\section{ACKNOWLEDGEMENTS}

We thank an anonymous reviewer for helpful comments on the manuscript. This work was supported by the SNF Grant \#31003A_146445 (to AO).

\section{REFERENCES}

Bachiorri A, Rossi V, Menozzi P, 1991. Differences in demographic parameters among electrophoretic clones of Daphnia obtusa Kurz (Crustacea: Cladocera). Hydrobiologia 225:263-268.

Bates D, Mächler M, Bolker BM, Walker SC, 2015. Fitting linear mixed-effects models using lme4. J. Stat. Softw. 67:1-48.

Benton TG, Grant A, 1999. Elasticity analysis as an important tool in evolutionary and population ecology. Trends Ecol. Evol. 14:467-471.

Bolker BM, Brooks ME, Clark CJ, Geange SW, Poulsen JR, Stevens MHH, White J-SS, 2009. Generalized linear mixed models: a practical guide for ecology and evolution. Trends Ecol. Evol. 24:127-135.

Bonacina C, 2001a. Lake Orta: the undermining of an ecosystem. J. Limnol. 60:53-59.

Bonacina C, 2001b. Has Lake Orta completely recovered from its heavy polluted condition? A seventy years long history. J. Limnol. 60:285-287.

Bonacina C, Baudo R, 2001. Lake Orta: a case study. a case study (Part 1). J. Limnol. 60:50-52.

Bonacina C, Pasteris A, 2001. Zooplankton of Lake Orta after liming: an eleven years study. J. Limnol. 60:101-109.

Calderoni A, Mosello R, Ruggiu D, 1992. Sixty years of limnology on Lago d'Orta: a case history of recovery from heavy pollution. Mem. Ist. Ital. Idrobiol. 50:201-223.

Caswell H, 2000. Prospective and retrospective perturbation analyses: their roles in conservation biology. Ecology 81: 619-627.

Caswell H, 2001. Matrix population models: construction, analysis, and interpretation. Second edition. Sinauer Associates, Sunderland: 722 pp.

Chevin L-M, Lande R, Mace GM, 2010. Adaptation, plasticity, and extinction in a changing environment: towards a predictive theory. PLoS Biol. 8:e1000357.

Coulson T, Tuljapurkar S, Childs DZ, 2010. Using evolutionary demography to link life history theory, quantitative genetics and population ecology. J. Anim. Ecol. 79:1226-1240.

Efron B, Tibshirani RJ, 1993. An introduction to the bootstrap. Chapman \& Hall/CRC, Boca Raton: 456 pp.

Ellner SP, Geber MA, Hairston Jr NG, 2011. Does rapid evolution matter? Measuring the rate of contemporary evolution and its impacts on ecological dynamics. Ecol. Lett. 14:603-614.

Hairston Jr NG, Ellner SP, Geber MA, Yoshida T, Fox JA, 2005. Rapid evolution and the convergence of ecological and evolutionary time. Ecol. Lett. 8:1114-1127.

Hülsmann S, Voigt H, 2002. Life history of Daphnia galeata in a hypertrophic reservoir and consequences of non-consump- tive mortality for the initiation of a midsummer decline. Freshwater Biol. 47:2313-2324.

Hülsmann S, Weiler W, 2000. Adult, not juvenile mortality as a major reason for the midsummer decline of a Daphnia population. J. Plankton Res. 22:151-168.

Kerfoot WC, Robbins JA, Weider LJ, 1999. A new approach to historical reconstruction: combining descriptive and experimental paleolimnology. Limnol. Oceanogr. 44:1232-1247.

Lampert W, 2001. Survival in a varying environment: phenotypic and genotypic responses in Daphnia populations. Limnetica 20:3-14.

Lopes I, Baird DJ, Ribeiro R, 2004. Genetic determination of tolerance to lethal and sublethal copper concentrations in field populations of Daphnia longispina. Arch. Environ. Contam. Toxicol. 46:43-51.

Medina MH, Correa JA, Barata C, 2007. Micro-evolution due to pollution: possible consequences for ecosystem responses to toxic stress. Chemosphere 67:2105-2114.

Merilä J, Hendry AP, 2014. Climate change, adaptation, and phenotypic plasticity: the problem and the evidence. Evol. Appl. 7:1-14.

Orsini L, Schwenk K, De Meester L, Colbourne JK, Pfrender ME, Weider LJ, 2013. The evolutionary time machine: using dormant propagules to forecast how populations can adapt to changing environments. Trends Ecol. Evol. 28:274-282.

Ozgul A, Tuljapurkar S, Benton TG, Pemberton JM, CluttonBrock TH, Coulson T, 2009. The dynamics of phenotypic change and the shrinking sheep of St. Kilda. Science 325:464-467.

Petchey OL, Pontarp M, Massie TM, Kéfi S, Ozgul A, Weilenmann M, Palamara GM, Altermatt F, Matthews B, Levine JM, Childs DZ, McGill BJ, Schaepman ME, Schmid B, Spaak P, Beckerman AP, Pennekamp F, Pearse IS, 2015. The ecological forecast horizon, and examples of its uses and determinants. Ecol. Lett. 18:597-611.

Piscia R, Colombini M, Ponti B, Bettinetti R, Monticelli D, Rossi V, Manca M, 2015. Lifetime response of contemporary versus resurrected Daphnia galeata Sars (Crustacea, Cladocera) to $\mathrm{Cu}(\mathrm{II})$ chronic exposure. Bull. Environ. Contam. Toxicol. 94:46-51.

Piscia R, Guilizzoni P, Fontaneto D, Vignati DAL, Appleby PG, Manca M, 2012. Dynamics of rotifer and cladoceran resting stages during copper pollution and recovery in a subalpine lake. Ann. Limnol. - Int. J. Lim. 48:151-160.

Piscia R, Seda J, Bonacina C, Manca M, 2006. On the presence of Daphnia galeata in Lake Orta (N. Italy). J. Limnol. 65:114-120.

Polishchuk LV, Vijverberg J, 2005. Contribution analysis of body mass dynamics in Daphnia. Oecologia 144:268-277.

Ponti B, Piscia R, Bettinetti R, Manca M, 2010. Long-term adaptation of Daphnia to toxic environment in Lake Orta: the effects of short-term exposure to copper and acidification. J. Limnol. 69:217-224.

R Development Core Team, 2014. R: A language and environment for statistical computing. R Foundation for Statistical Computing, Vienna, Austria.

Young JD, Strecker AL, Yan ND, 2011. Increased abundance of the non-indigenous zooplanktivore, Bythotrephes longimanus, is strongly correlated with greater spring prey availability in Canadian Shield lakes. Biol. Invasions 13:2605-2619. 